\section{BMJ Open \\ Respiratory \\ Research}

\title{
Effect of inhaled corticosteroids on blood eosinophil count in steroid-naïve patients with COPD
}

\author{
James L Kreindler, ${ }^{1}$ Michael L Watkins, ${ }^{2}$ Sally Lettis, ${ }^{3}$ Ruth Tal-Singer, ${ }^{1}$ \\ Nicholas Locantore ${ }^{1}$
}

To cite: Kreindler JL, Watkins ML, Lettis S, et al. Effect of inhaled corticosteroids on blood eosinophil count in steroidnaïve patients with COPD. BMJ Open Resp Res 2016;3: e000151. doi:10.1136/ bmjresp-2016-000151

Received 6 July 2016 Accepted 3 August 2016

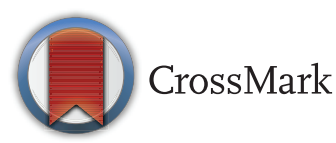

${ }^{1}$ GSK R\&D, King of Prussia, Pennsylvania, USA ${ }^{2}$ GSK R\&D, Research Triangle Park, North Carolina, USA

${ }^{3}$ GSK R\&D, Uxbridge, UK

Correspondence to Dr James L Kreindler; james.l.kreindler@gsk.com

\section{ABSTRACT}

Introduction: Sputum and blood eosinophil counts have attracted attention as potential biomarkers in chronic obstructive pulmonary disease (COPD). One question regarding the use of blood eosinophils as a biomarker in COPD is whether their levels are affected by the use of inhaled corticosteroids (ICS), which are commonly prescribed for COPD.

Methods: We performed a retrospective analysis of peripheral blood leucocytes from a previously completed clinical trial that examined effects of ICS in steroid-naïve patients with COPD.

Results and conclusion: The data show that the ICS-containing treatment arms (containing fluticasone propionate) had a small effect on peripheral blood eosinophils in steroid-naiive patients with COPD.

Trial registration number: NCT00358358; Post-results.

\section{INTRODUCTION}

Chronic obstructive pulmonary disease (COPD) is a heterogeneous disease for which there are limited choices with respect to therapeutic mechanisms of action. In order to direct patient-specific therapy in a disease with high prevalence and high clinical variability, the medical community needs to identify and scientifically validate COPD biomarkers.

Sputum and blood eosinophil counts have attracted attention as potential biomarkers. For example, higher sputum eosinophil counts in patients with COPD predicts clinical response to inhaled corticosteroids (ICS), ${ }^{1}$ as it does for anti-interleukin 5 (IL5) therapy in asthma. ${ }^{2}$ Peripheral blood eosinophil count was proposed more recently as a biomarker to direct corticosteroid therapy during COPD exacerbations $^{3}$ and to select those who will benefit from medicines containing ICS. ${ }^{45}$ Currently, blood eosinophil levels are being studied in clinical trials assessing the efficacy of anti-IL5 therapies such as mepolizumab (NCT02105948) and benralizumab (NCT02138916) in patients with COPD.

\section{KEY MESSAGES}

Inhaled corticosteroids have a small effect on peripheral blood eosinophil counts.

- The effect is likely small enough on average not to affect patient stratification using cut-off values.

One question regarding the use of blood eosinophils as a biomarker in COPD is whether their levels are affected by the use of ICS, which are commonly prescribed for COPD. Our post hoc analysis of an interventional study in steroid-naïve patients with COPD evaluated the extent to which ICS affected blood eosinophil counts and compared the distribution of baseline eosinophil counts in the study with the COPD and non-COPD control cohorts from (Evaluation of COPD Longitudinally to Identify Predictive Surrogate End points) ECLIPSE.

\section{METHODS}

Study design

SCO104925 (NCT00358358) was a 12-week, double-blind, parallel-group study comparing patients randomised to receive placebo, fluticasone propionate $[\mathrm{FP}] /$ salmeterol combination (FSC) or the individual components of FSC (FP or salmeterol). Individuals were included if they had COPD as defined by a post salbutamol forced expiratory volume in $1 \mathrm{~s}\left(\mathrm{FEV}_{1}\right) /$ forced vital capacity (FVC) $\leq 70 \%$ and a post salbutamol $\mathrm{FEV}_{1} \geq 30 \%$ and $\leq 70 \%$ of predicted. Individuals were excluded if they used oral corticosteroids or ICS-containing products for more than 14 consecutive days in the prior 6 months or at any time within 30 days of screening.

In this post hoc analysis, we examined blood eosinophil counts from complete blood counts that were measured at baseline, and week 6 and 12, providing an opportunity to 
Table 1 Baseline patient characteristics and eosinophil counts during the study

\begin{tabular}{|c|c|c|}
\hline Baseline characteristics & Non-ICS arms $(n=59)$ & ICS arms $(n=53)$ \\
\hline Age, years & $66(61$ to 71$)$ & $64(54$ to 71$)$ \\
\hline Male, \% & 80 & 74 \\
\hline Smoking history, pack-years & 46 (33 to 55$)$ & $42(26$ to 60$)$ \\
\hline Current smoker, \% & 51 & 55 \\
\hline Post-bronchodilator $\mathrm{FEV}_{1}, \mathrm{~L}$ & $1.40(1.07$ to 1.65$)$ & $1.50(1.15$ to 1.87$)$ \\
\hline Post-bronchodilator FEV 1 per cent predicted & $50(40$ to 61$)$ & 55 (45 to 63$)$ \\
\hline Eosinophil counts, cells/ $\mu \mathrm{L}$ & Non-ICS arms $(n=59)$ & ICS arms $(n=53)$ \\
\hline Eosinophil count at baseline & $230(120$ to 410$)$ & $200(120$ to 310$)$ \\
\hline Change, week 6 & $-20(-80$ to 70$)$ & $-30(-90$ to 10$)$ \\
\hline Change, week 12 & $10(-80$ to 80$)$ & $-30(-90$ to 20$)$ \\
\hline Percentage of patients with eosinophil count at baseline $\geq 150$ & 71 & 66 \\
\hline Percentage of patients with eosinophil count at baseline $\geq 300$ & 34 & 26 \\
\hline
\end{tabular}

Values presented as median (IQR) unless otherwise noted.

FEV1, forced expiratory volume in 1s; ICS, inhaled corticosteroids; IQR, interquartile range.

examine the impact of steroid-containing therapies on blood eosinophils in a steroid-naïve COPD population.

The patients for this post hoc analysis consisted of those persons who completed the study and had eosinophil levels available for all time points. Additionally, to eliminate potential confounding, persons who had an exacerbation or received oral corticosteroids during the study period were excluded.

The design of the ECLIPSE observational study (SCO104960, NCT00292552) has been published elsewhere. ${ }^{6}$ Briefly, patients with COPD had a smoking history $\geq 10$ pack-years, a post-bronchodilator $\mathrm{FEV}_{1} / \mathrm{FVC}$ ratio $<0.7$ and an $\mathrm{FEV}_{1}<80 \%$ of predicted. Controls (with or without smoking history) had $\mathrm{FEV}_{1} / \mathrm{FVC}>70 \%$ and $\mathrm{FEV}_{1}>85 \%$.

Both studies were sponsored by GSK and conducted according to Good Clinical Practice and in accordance with guidelines from the Declaration of Helsinki. Each study protocol was approved by relevant ethical boards and institutional review boards at participating centres.

\section{Statistical methods}

Owing to the small sample size for the study and the presence of outliers, summaries for continuous variables are provided as median and IQR; categorical summaries are presented as percentages. Hodges-Lehmann estimates $^{7}$ and associated 95\% CIs for the difference in location shift of changes in blood eosinophil counts between the ICS-treated and non-ICS-treated groups were calculated based on Wilcoxon rank-sum tests. The comparisons of the baseline distribution of blood eosinophil counts for SCO104925 and the ECLIPSE cohorts used two-sample Kolmogorov-Smirnov tests.

\section{RESULTS}

Overall, 161 persons were randomised to treatment in study SCO104925, with 80 assigned to non-ICS-containing treatments (salmeterol or placebo) and 81 to ICScontaining treatments (FSC or FP). One hundred and fourty-three patients completed the 12-week study; 73 from the non-ICS-treated patients and 70 from the ICS-treated patients. To remove potential confounding factors, patients who either had an exacerbation and/or were prescribed oral corticosteroids during the treatment period were excluded. Accounting for these factors, 59 patients from the non-ICS-treated arms and 53 patients from the ICS-treated arms (112 total patients) were used in this post hoc analysis.

The primary and key secondary outcome measures for SCO104925 measured the impact of ICS on impulse oscillometry and lung imaging end points in steroidnaïve patients with COPD. ${ }^{8}$ These results are not germane to this retrospective analysis of blood eosinophils and, therefore, will not be further discussed.

\section{Changes in blood eosinophil counts}

In SCO104925, median (IQR) blood eosinophil count was 200 (120 to 310$)$ cells $/ \mu \mathrm{L}$ at baseline for patients who received ICS during treatment, and 230 (120 to 410) cells $/ \mu \mathrm{L}$ for patients not receiving ICS during treatment. Median (IQR) changes in eosinophil count for ICS-treated patients were -30 ( -90 to 10$)$ cells $/ \mu \mathrm{L}$ at

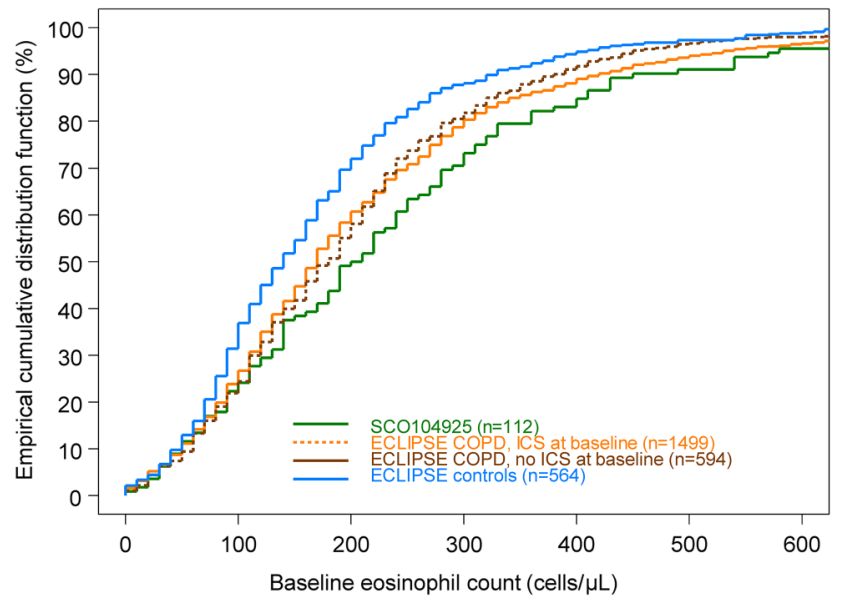

Figure 1 Empirical distribution function for SCO104925 patients and the ECLIPSE cohorts. 
week 6 and -30 (-90 to 20 ) cells $/ \mu \mathrm{L}$ at week 12 , while median (IQR) changes for non-ICS-treated patients were -20 ( -80 to 70$)$ cells $/ \mu \mathrm{L}$ at week 6 and 10 ( -80 to 80) cells $/ \mu \mathrm{L}$ at week 12 . The differences in eosinophil count changes between groups were not significant at week 6 (median $(95 \% \mathrm{CI})$ difference -20 (-60 to 20); $\mathrm{p}=0.315)$ nor at week 12 (median $(95 \% \mathrm{CI}$ ) difference -40 (80 to 10$) ; \mathrm{p}=0.090$ ). However, this may be due to lack of power for these comparisons based on the size of the study. Study characteristics and eosinophil levels are shown in table 1.

\section{Comparison of baseline distribution of blood eosinophil counts}

To contextualise the findings from SCO104925, the distribution of baseline blood eosinophil counts in
SCO104925 patients was compared with those in the ECLIPSE study. The baseline eosinophil counts of non-COPD controls in the ECLIPSE study were distributed differently (lower values) than the eosinophil counts of patients with COPD in ECLIPSE and SCO104925 ( $p<0.001$ for both comparisons with controls). The distribution of blood eosinophils for SCO104925 patients was not significantly different from either the ECLIPSE COPD cohort reporting ICS use $(\mathrm{p}=0.102)$ or those not reporting ICS use $(p=0.137)$. Consistent with ICS having a small effect on blood eosinophil counts, there was no significant difference in the distribution of blood eosinophil counts in ECLIPSE patients reporting ICS use at baseline compared with those patients not reporting ICS use $(p=0.246$; figure 1$)$. Summary statistics for each cohort are shown in table 2.

Table 2 Summary of eosinophil counts at baseline for the ECLIPSE study

\begin{tabular}{|c|c|c|c|}
\hline $\begin{array}{l}\text { Baseline eosinophils, } \\
\text { cells/ } \mu \mathrm{L}\end{array}$ & $\begin{array}{l}\text { COPD: ICS use at baseline } \\
(n=1499)\end{array}$ & $\begin{array}{l}\text { COPD: no ICS use at baseline } \\
(n=594)\end{array}$ & $\begin{array}{l}\text { Non-COPD controls } \\
(n=564)\end{array}$ \\
\hline $\begin{array}{l}\text { Eosinophil count, } \\
\text { median (IQR) }\end{array}$ & 180 (110 to 290$)$ & 190 (120 to 270$)$ & 150 (90 to 230$)$ \\
\hline $\begin{array}{l}\text { Eosinophil count } \\
\geq 150 \text { cells/ } \mu \mathrm{L}, \mathrm{n}(\%)\end{array}$ & $918(61)$ & $374(63)$ & $290(51)$ \\
\hline $\begin{array}{l}\text { Eosinophil count } \\
\geq 300 \text { cells/ } \mu \mathrm{L}, \mathrm{n}(\%)\end{array}$ & $347(23)$ & $121(20)$ & $73(13)$ \\
\hline
\end{tabular}

A

A Baseline

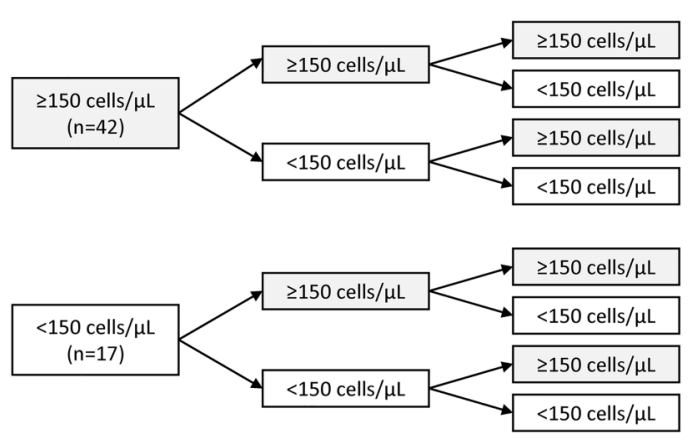

C Baseline
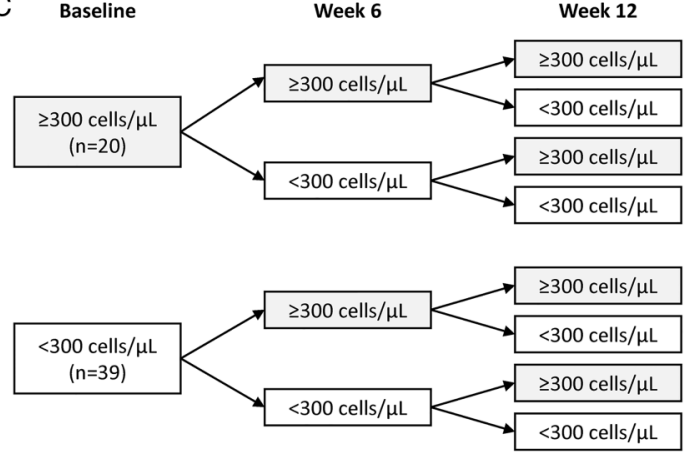

B Baseline

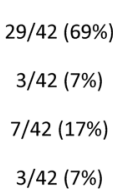

$5 / 17(29 \%)$

$2 / 17(12 \%)$

$5 / 17(29 \%)$

$5 / 17(29 \%)$

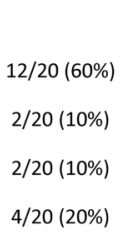

D Baseline

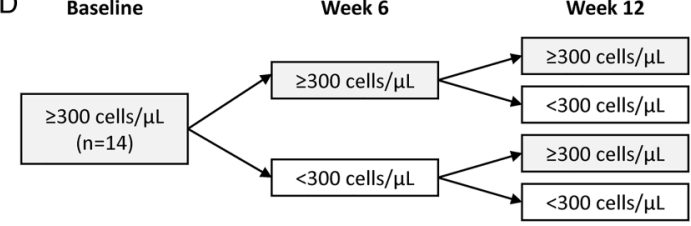

4/14 (29\%)

$2 / 14$ (14\%)

2/14 (14\%)

$6 / 14(43 \%)$

$2 / 39(5 \%)$

$3 / 39(8 \%)$

$2 / 39(5 \%)$

$32 / 39(82 \%)$

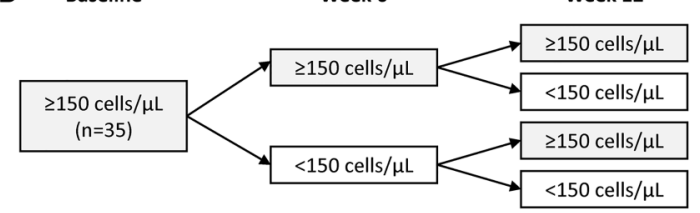

26/35(74\%)

$3 / 35(9 \%)$

2/35 (6\%)

$4 / 35(11 \%)$

$5 / 18(28 \%)$

2/18 (11\%)

$1 / 18(6 \%)$

10/18 (56\%)

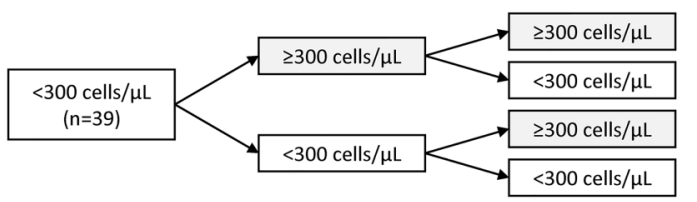

0/39 (0\%)

1/39 (3\%)

2/39 (5\%)

$36 / 39$ (92\%)

Figure 2 Peripheral blood eosinophil levels based on a threshold of $(A) 150$ cells/ $\mu \mathrm{L}$, patients not randomised to inhaled corticosteroids (ICS)-containing treatment $(n=59)$, (B) 150 cells $/ \mu \mathrm{L}$, patients randomised to ICS-containing treatment $(n=53)$, (C) 300 cells $/ \mu \mathrm{L}$, patients not randomised to ICS-containing treatment $(n=59)$ and (D) 300 cells $/ \mu \mathrm{L}$, patients randomised to ICS-containing treatment $(n=53)$. 
As some of the recent discussion regarding blood eosinophils as a biomarker to direct treatment revolves around threshold values, we investigated changes in peripheral blood eosinophil levels based on thresholds and found that although the majority of patients remain in their baseline category, there is some regression to the mean with respect to using thresholds (figure 2).

\section{DISCUSSION}

The desire to practice precision medicine has prompted a broad, intensive search for biomarkers that can be used to direct personalised therapy in COPD. Eosinophils have been part of this search for more than a decade. ${ }^{9}$ Much of the early focus was on sputum eosinophils as a direct marker of lung inflammation. The data presented here do not directly address the effect of ICS on sputum eosinophils, as sputum was not collected in the SCO104925 trial. However, there are data to suggest that changes in sputum eosinophil count due to titration of ICS therapy ${ }^{10}$ or discontinuation of ICS therapy ${ }^{11}$ correlate with COPD exacerbations, although not all studies have shown a significant change in sputum eosinophils in response to ICS therapy in patients with COPD. ${ }^{12}$ As measuring sputum eosinophils can be technically difficult and may not be feasible for many practitioners caring for patients with COPD, there is interest in blood eosinophils as a more practicable alternative. The potential importance of blood eosinophils as a biomarker is highlighted by recent clinical trial data. ${ }^{45}$ The data presented here show ICS-containing treatments having a small effect on blood eosinophil levels in steroid-naïve patients. The lack of a pronounced effect suggests that peripheral blood eosinophil level reduction per se may not be the mechanism for the clinical efficacy seen with ICS in COPD, despite peripheral blood eosinophils being identified as a potential biomarker for enhanced exacerbation reduction with inhaled and oral corticosteroid-containing medications.

Contributors All authors were involved in the conception of the study and interpretation of data. NL and SL were involved in the analysis of the data. All authors were involved in the drafting and revising of the manuscript for important intellectual content, and all provided approval of the final manuscript. The authors agree to be accountable for all aspects of the work in ensuring that questions related to the accuracy or integrity of any part of the work are appropriately investigated and resolved.
Funding The studies included in this post hoc analysis were funded by GSK (study codes SC0104925 and SC0104960, clinicaltrials.gov ID NCT00358358 and NCT00292552).

Competing interests JLK, MLW, SL, RT-S and NL are employees of GSK and hold shares in the company.

Ethics approval Approved by relevant ethical boards and institutional review boards at participating centres.

Provenance and peer review Not commissioned; internally peer reviewed.

Data sharing statement No additional data are available.

Open Access This is an Open Access article distributed in accordance with the terms of the Creative Commons Attribution (CC BY 4.0) license, which permits others to distribute, remix, adapt and build upon this work, for commercial use, provided the original work is properly cited. See: http:// creativecommons.org/licenses/by/4.0/

\section{REFERENCES}

1. Brightling CE, McKenna S, Hargadon B, et al. Sputum eosinophilia and the short term response to inhaled mometasone in chronic obstructive pulmonary disease. Thorax 2005;60:193-8.

2. Ortega HG, Liu MC, Pavord ID, et al. Mepolizumab treatment in subjects with severe eosinophilic asthma. N Engl J Med 2014;371:1198-207.

3. Bafadhel M, McKenna S, Terry S, et al. Blood eosinophils to direct corticosteroid treatment of exacerbations of chronic obstructive pulmonary disease: a randomized placebo-controlled trial. Am J Respir Crit Care Med 2012;186:48-55.

4. Pascoe S, Locantore N, Dransfield MT, et al. Blood eosinophil counts, exacerbations, and response to the addition of inhaled fluticasone furoate to vilanterol in patients with chronic obstructive pulmonary disease: a secondary analysis of data from two parallel randomised controlled trials. Lancet Respir Med 2015;3:435-42.

5. Siddiqui SH, Guasconi A, Vestbo J, et al. Blood eosinophils: a biomarker of response to extrafine beclomethasone/formoterol in chronic obstructive pulmonary disease. Am J Respir Crit Care Med 2015;192:523-5.

6. Vestbo J, Anderson W, Coxson HO, et al. Evaluation of COPD Longitudinally to Identify Predictive Surrogate End-points (ECLIPSE). Eur Respir J 2008;31:869-73.

7. Hodges JR, Lehmann EL. Estimates of location based on rank tests. Ann Math Stat 1963;34:598-611.

8. Summary: CTR Summary for MDC_-GSK Clinical Study Register. http://www.gsk-clinicalstudyregister.com/files2/21078.pdf (accessed 1 Aug 2016)

9. Pizzichini E, Pizzichini MM, Gibson P, et al. Sputum eosinophilia predicts benefit from prednisone in smokers with chronic obstructive bronchitis. Am J Respir Crit Care Med 1998;158(Pt 1):1511-17.

10. Siva $\mathrm{R}$, Green $\mathrm{RH}$, Brightling $\mathrm{CE}$, et al. Eosinophilic airway inflammation and exacerbations of COPD: a randomised controlled trial. Eur Respir J 2007;29:906-13.

11. Liesker JJ, Bathoorn E, Postma DS, et al. Sputum inflammation predicts exacerbations after cessation of inhaled corticosteroids in COPD. Respir Med 2011;105:1853-60.

12. Keatings VM, Jatakanon A, Worsdell YM, et al. Effects of inhaled and oral glucocorticoids on inflammatory indices in asthma and COPD. Am J Respir Crit Care Med 1997;155:542-8. 